\title{
CONFIGURACIONES MIGRATORIAS: UNA REFLEXIÓN PARA TRES ESCENARIOS ALEMANES
}

\author{
Migratory Configurations: A Reflection for Three German Scenarios
}

\author{
Menara Guizardi* \\ Pablo Mardones*
}

\begin{abstract}
Resumen. El artículo presenta una reflexión etnográfica sobre las configuraciones de la experiencia migrante en siete ciudades de tres estados alemanes. Partiremos por situar, en el segundo apartado, el contexto migratorio en Alemania, a través de una síntesis de datos oficiales estadísticos. En el tercero, presentamos nuestras observaciones sobre el contexto migratorio en las ciudades del estado de Turingia. En el cuarto, en las ciudades de Hesse y, en el quinto, en las de Renania del Norte-Westfalia. Cerramos con reflexiones sobre las configuraciones migrantes en estos tres territorios de Alemania.
\end{abstract}

Palabras clave: migraciones; refugio; Alemania; etnografía; política pública.

\begin{abstract}
The article presents an ethnographic reflection on the configurations of the migrant experience in seven cities of three German states. We will start by situating, in the second section, the migratory context in Germany, through a synthesis of official statistical data. In the third, we present our observations on the migration context in the cities of the state of Thuringia. In the fourth, in the cities of Hesse and, in the fifth, in those of North Rhine-Westphalia. We close with reflections on the migrant configurations in these three territories of Germany.
\end{abstract}

Keywords: migrations; refuge; Germany; ethnography; public policy.

\section{Introducción}

En inicios de febrero de 2019, fuimos a conocer los centros de investigación de tres universidades alemanas que integran la red Maria Sibylla Merian de Estudios Latinoamericanos Avanzados en Humanidades y Ciencias

Consejo Nacional de Investigaciones Científicas y Técnicas de Argentina e Instituto de Altos Estudios Sociales de la Universidad Nacional de San Martín. Buenos Aires, Argentina. Universidad de Tarapacá. Arica, Chile. E-mail: menaraguizardi@yahoo.com.br. Orcid: 0000-0003-2670-9360.

** Instituto de Estudios Internacionales (INTE) de la Universidad Arturo Prat. Iquique, Chile. E-mail: mardones.pablo@gmail.com. Orcid: 0000-0002-4490-1391. 
Sociales (CALAS). Esta red, financiada con fondos del Ministerio Federal de Educación e Investigación del Gobierno de Alemania, articula un consorcio de cuatro instituciones germánicas y otras cuatro latinoamericanas que investigan los procesos de crisis (medioambientales, identitarias, de desigualdad y de violencia) en América Latina y Caribe ${ }^{1}$.

Representando al centro CALAS de la Universidad Nacional de San Martín (Buenos Aires, Argentina), Menara Guizardi viajó con un colega experto en desigualdades sociales, Lucas González², a discutir las crisis migratorias y el agravamiento de las desigualdades sociales que vienen caracterizando el "giro a la derecha" en los países del Cono Sur Americano -particularmente, Argentina, Brasil y Chile-. Pablo Mardones se integró a los debates y encuentros, realizando un registro visual de la experiencia académica.

En el marco de este viaje, nos propusimos a desarrollar, entre los días 2 y 11 de febrero de 2019, una etnografía de las configuraciones de la experiencia migrante en siete ciudades de tres estados alemanes: Turingia, Hesse, y Renania del Norte-Westfalia.

La etnografía consiste en la observación sistemática de los contextos sociales con la finalidad de, simultáneamente, participar de ellas, registrarlas, analizarlas y construir relatos (en nuestro caso particular, contemplamos no solo el relato escrito, sino también el visual). Además, la perspectiva metodológica etnográfica busca la interacción crítica entre sujetos de estudio e investigadores. Por lo mismo, la etnografía es un enfoque, un método y un ejercicio de relato de carácter intersubjetivo (Guber, 2001, p. 12).

Nuestro enfoque etnográfico siguió, en nuestras visitas a todas las ciudades, las delimitaciones del Extended Case Method (ECM) [Metodología del Caso Extendido], también conocido como Situational Analysis [análisis situacional]. Dicho enfoque fue desarrollado por Max Gluckman y sus discípulos en el marco de la Escuela de Manchester (Evens, Handelman, 2006; Frankenberg, 2006), apoyándose en los estudios etnográficos sobre procesos de colonización, migración, urbanización y conflictos raciales (y étnicos) en

\footnotetext{
1 La red en Alemania está compuesta por: 1) el Centro Internacional de Estudios Transdisciplinarios Argentina/ Cono Sur (ARCOSUR) de la Universidad Friedrich-Schiller (en la ciudad de Jena); 2) el Centro de Estudios Latinoamericanos (CELA) de la Universidad de Kassel (en la misma Kassel); 3) Center for Interamerican Studies (CIAS) de la Universidad de Bielefeld (en Bielefeld) y 4) Centro de Estudios Atlánticos y Globales de la Universidad Leibniz (en Hanover). En América Latina, CALAS cuenta con: 1) un centro regional para el Cono Sur, en la Universidad Nacional de San Martín (Buenos Aires, Argentina); 2) uno para la región andina, en la Facultad Latinoamericana de Ciencias Sociales (en Quito, Ecuador); 3) uno en México, en la Universidad de Guadalajara y 4) uno para Centro América y el Caribe, en el Centro de Investigaciones Históricas de América Central (CIHAC) de la Universidad de Costa Rica, en San José.

2 Investigador del Consejo Nacional de Investigaciones Científicas y Técnicas de Argentina y de Escuela de Política y Gobierno de la Universidad Nacional de San Martín (Buenos Aires, Argentina). Agradecemos a González su compañía en terreno, sus reflexiones y su atenta revisión de este texto.
} 
contextos sudafricanos (Frakenberg, 2006; Kempny, 2006). Aboga por la realización de la etnografía en equipo y propone reorientar la metodología antropológica clásica (Burawoy, 1998, p. 6). Por lo mismo, implica al menos tres aspectos que lo diferencian de los abordajes etnográficos considerados clásicos: 1) en vez de recortar de forma descontextualizada los ejemplos etnográficos usándolos para reforzar concepciones generales preestablecidas, se propone llegar a lo general desde las particularidades del caso (Burawoy, 1998, p. 5; Evens, Handelman, 2006, p. 5). 2) Se desarrolla a partir del estudio de interacciones sociales con potencial conflictivo (Gluckman, 2006, p. 17). 3) Con el objetivo de comprender diacrónicamente las situaciones sociales observadas, la estrategia analítica presupone identificar procesos históricos que inciden en la experiencia cotidiana (Glaeser, 2006, p. 78-79; Mitchell, 2006, p. 29).

A partir de estas orientaciones metodológicas, registramos nuestras visitas a las siete ciudades y las relaciones en ellas observadas en diarios de campo y también a partir de una serie de fotografías etnográficas. Nuestras visitas y observaciones han sido acompañadas por investigadores de diferentes campos de las ciencias sociales -antropología, sociología, geografía urbana- que trabajan sobre los territorios visitados. Por lo mismo, nuestros análisis fueron interpelados por los diálogos y conversaciones sostenidas con estos colegas, al que vamos mencionando progresivamente en los diferentes apartados del texto.

El objetivo del presente artículo es, precisamente, presentar y discutir las interpretaciones comparativas que producimos a partir de las conversaciones con colegas investigadores, de las visitas a espacios migratorios y de los registros visuales. Como explicaremos a lo largo del texto, este ejercicio comparado nos permite desarticular mitos sobre los modelos de manejo de las cuestiones migratorias en los países sudamericanos y europeos.

Para dar cuenta de los resultados de nuestra etnografía, partiremos por situar, en el segundo apartado, las actuales configuraciones de las migraciones en Alemania, con la síntesis de datos oficiales estadísticos. En el tercer apartado, presentamos nuestras observaciones sobre el contexto migratorio en las ciudades del estado de Turingia. En el cuarto, en las ciudades de Hesse y, en el quinto, en las de Renania del Norte-Westfalia. En el último apartado, discutimos nuestras reflexiones sintéticas sobre las configuraciones migrantes en estos tres territorios de Alemania.

\section{Configuraciones migratorias}

Desde 2005, Alemania es el segundo principal destino migratorio global, detrás de EEUU (IOM, 2018, p. 18). En 2016, el país recibió 720.000 solicitudes de asilo, convirtiéndose en el mayor receptor de refugiados del mundo (IOM, 2018, p. 32). Este escenario deflagró una crisis migratoria, 
y resultó particularmente novedoso para aquellas regiones alemanas que, en la segunda mitad del siglo XX, no fueron ejes receptores de migración internacional ${ }^{3}$. Las estadísticas demográficas nacionales reflejan la envergadura de este escenario: entre 2017 y 2014, Alemania mantuvo números absolutos de población extranjera (incluyéndose los solicitantes de refugio) de cerca de 7 millones de personas ${ }^{4}$. En 2014, estos números se incrementan, con el registro de 8.152.970 migrantes (entre los cuales 1.036.235 era refugiados) (DESTATIS, 2019a). Para diciembre de 2017, se registraban 10.623 .940 migrantes, con 1.680.700 refugiados entre ellos (DESTATIS, 2019a).

La población alemana apenas registró crecimiento demográfico en la última década. En 2007, el país contaba con un total de 82.217.837 habitantes (incluyendo migrantes y refugiados). En fines de 2017, este número giraba alrededor de 82.792.351 personas (DESTATIS, 2019a): el país envejece y presenta tasas descendientes de recambio demográfico. Así, la llegada de extranjeros constituye el principal elemento de equilibrio para la tendencia de decrecimiento poblacional (especialmente de los grupos en edad económicamente activa) (Awojobi, 2016, p. 143). En 2017, la diferencia entre la población que "inmigra a" y la que "emigra de" Alemania fue de 416.000 personas: entraron al país 1,9 millones de migrantes, pero unos 1,5 millones de personas dejaron sus fronteras (DESTATIS, 2019b). Desde 2000, Alemania consta en el ranking de los 10 principales países receptores (IOM, 2018, p. 31) y también emisores (IOM, 2018, p. 32) de remesas migratorias.

Según los últimos datos del Servicio Federal de Estadísticas de Alemania, entre la totalidad de extranjeros (computándose migrantes y refugiados), los colectivos nacionales más numeroso provienen de Turquía (1.500.000 personas), Polonia (866.855) y Siria (698.950). Fijándonos solamente en los solicitantes de refugio, los tres colectivos predominantes serían de Siria (507.190), Afganistán (204.180) e Irak (177.400) (DESTATIS, 2019c). Empero, la importancia cultural y la envergadura de la migración en el país se nota más claramente en otros cómputos: el 56\% de los hogares alemanes cuentan con hasta un integrante con "historial migrante" [migrant background] ${ }^{5}$.

3 Esta crisis resulta de la intervención bélica (y de la injerencia política), por parte de Estado Unidos y Europa, en países de oriente medio -Afganistán, Irak, Siria-, que, sumergidos en conflictos de larga duración, expulsan población masivamente (Kretsedemas, Brotherton, 2018). Pero también resulta de la aplicación de tecnología bélica para la vigilancia de las fronteras europeas en el Mediterráneo (que, desde 2015, es el lugar del mundo donde más mueren migrantes). El intento de "cierre militar" del Mediterráneo y de las fronteras polonesas reorientó las nuevas rutas terrestres a través de espacios continentales europeos, cruzando territorios alemanes que no configuraban espacios receptores migratorios.

4 Unas 6.744.880 personas en 2007 (entre las cuales 457.430 eran solicitantes de refugio) y 7.213.710 en 2012 (incluyendo a 549.825 solicitantes de refugio) (DESTATIS, 2019a).

5 El gobierno alemán considera que una persona tiene historial migrante si al menos uno de sus padres no adquirió nacionalidad alemana al momento de nacer (DESTATIS, 2019c). 
Aproximadamente 19,3 millones de personas en Alemania tienen historial migrante: entre ellas el $17 \%$ tiene familiares turcos, $15 \%$ rusos, $8 \%$ polacos y 7\% árabes (DESTATIS, 2019c).

\section{Turingia}

Nuestra primera parada fue en el estado federado de Turingia (centrooriente alemán): epicentro de la reforma protestante de Lutero (siglo XVI) $y$, junto con Sajonia, foco inicial de la revolución industrial alemana (siglo XIX). Precisamente por su gran parque industrial, Turingia fue severamente bombardeada en la Segunda Guerra Mundial. Tras el conflicto, fue integrada a la República Democrática Alemana (RDA), de gobierno socialista. A diferencia de lo que pasó con los estados del lado occidental de Alemania en los años de Guerra Fría -en especial entre la construcción (1961) y la caída (1989) del muro de Berlín-, Turingia no fue foco receptor de flujos migrantes internacionales ${ }^{6}$.

Tras la reunificación iniciada en los 1990s, las ciudades de la región vienen protagonizando un complejo proceso de reconfiguración de su economía, identidad, arquitectura y vínculos sociales (financiado con recursos públicos del Estado alemán y de la Unión Europea). Con todo, Turingia abriga algunas de las ciudades con menores niveles de desarrollo humano (medidos a través del índice GINI) en el contexto alemán. Por lo mismo, es destinataria de recursos estatales de saneamiento económico que son aplicados para la seguridad social, fomento productivo y desarrollo de infraestructuras urbanas. Todo esto se ve claramente en las nuevas y recién reformadas fachadas de los edificios de sus ciudades; en la densidad de sus redes de transporte por tren, tranvía y bus y en el impresionante despliegue infraestructural de sus universidades públicas (que son el corazón social de muchas ciudades de la región).

Acompañados por una investigadora experta en la reconversión de las ciudades de la ex Alemania oriental, la Dra. Claudia Tomadoni (Universidad Friedrich-Schiller), visitamos dos ciudades de Turingia: Jena (110.000 habitantes) y Weimar (65.000 habitantes) $)^{7}$. Junto con Erfurt (capital del estado con 210.000 residentes), ellas son consideradas "ciudades intermedias" alemanas y forman una tríade urbana interconectada por una densa red de transportes. Aquí conocimos un modelo particular de tratamiento a la cuestión migratoria.

\footnotetext{
6 La Guerra Fría entre el bloque capitalista y el comunista en Europa engendró una diferencia de significados atribuidos a las migraciones en estos dos regímenes. La libertad migratoria interna e internacional era comprendida como elemento distintivo del mundo capitalista en oposición a la política de control de los desplazamientos en los países comunistas. En estos, las movilidades poblacionales (sobre todo hacia las ciudades industriales o estratégicas en términos militares) estaban sujetas al control del Estado (Gang, Stuart, 1999).

Sede de la "República de Weimar" (1918-1933), en la cual fue promulgada la primera constitución de corte social de Europa, en 1919. Nuestra visita coincidió con el inicio de la celebración de los cien años de esta constitución.
} 
Un primer aspecto central para entender las políticas migratorias alemanas refiere al elevado nivel de descentralización funcional del gobierno federal. Los 16 estados gozan de gran autonomía para decidir cómo y en qué medida aplicar las directrices de las políticas Estado-nacionales. Estas decisiones son redirigidas a las administraciones municipales: cada ciudad elige de forma particular -en consonancia con los contextos productivos, políticos y culturales locales-, cómo implementar los lineamientos del gobierno central y de los estados en los que se sitúan ${ }^{8}$. Así, la política migratoria es definida en rasgos amplios por el gobierno federal, pero su aplicación puede variar entre los diferentes estados y, dentro de ellos, entre cada ciudad.

Caminando por las calles del centro de Jena y Weimar, nos Ilamó la atención no encontrar aglomeraciones de negocios turcos que constituyen el paisaje de varias ciudades alemanas. La explicación refiere a factores históricos: como son ciudades del antiguo lado oriental, no contaron con la histórica migración turca y, por lo mismo, los centros urbanos no presentan estos aspectos de una economía migratoria arraigada y con elevado nivel de transnacionalismo. Según Tomadoni, entre 2015 y 2016 la llegada masiva de refugiados a las inmediaciones de estas ciudades provocó gran conmoción social: contingentes sirios muy numerosos se instalaron en campos en el extrarradio urbano. La emergencia humanitaria -los refugiados venían con desnutrición, deshidratación, heridas, insuficientes abrigos, había niños desacompañados y dormían a intemperie- movilizó parte de la población de Weimar y Jena que se voluntarió a trabajar en la solución de estas urgencias vitales.

Pasados los momentos iniciales de atención humanitaria (para la cual se destinaron sendos recursos de la Unión Europea) y suscitando profundas controversias políticas, la jefa del poder ejecutivo, Angela Merkel (Unión Democrática Cristiana), decidió desplegar recursos estatales federales para promover un gran plan inicial de asentamiento de estas poblaciones (Awojobi, 2016, p. 142) ${ }^{9}$. Este plan proponía distribuir recursos públicos a los estados

8 Esto refiere, a su vez, a la configuración histórica de las ciudades y su ordenamiento político en los territorios que actualmente conforman Alemania. Como discutieron, Hobsbawn (1998) y Zapata (2001), las ciudades alemanas constituían, desde el renacimiento urbano en la baja edad media, núcleos políticos con gobierno propio. En ellos, la identidad cultural, política y económica de los habitantes estaba articulada a la pertenencia al territorio urbano: la noción de "ciudadanía" surgió, primero, como la definición del vínculo a una ciudad específica. Esto explica, al menos en parte, porqué la unificación alemana bajo los principios del Estado-nacional moderno -que supone la invención de una identificación comunitaria abstracta, por sobre las vinculaciones locales (Anderson, 1993)- fue tardía en comparación con países como Francia (Brubaker, 1992). Localidades como Weimar y Jena detentan, hasta la actualidad, el título de "ciudades libres".

9 Paralelamente, Alemania lideró las negociaciones de la Unión Europea con Turquía para el cierre de las fronteras del país y para que este operara como receptor de los refugiados sirios desde 2016 en adelante (recibiendo para ello armamentos, tecnología militar de control fronterizo y la transferencia de un estipendio monetario para cada refugiado arraigado). 
y ciudades que se alistaran a recibir población refugiada. Cada ciudad debía elegir si quería o no recibir extranjeros y, en el caso de hacerlo, podía designar un cupo de recepción. Además, podía crear su propio plan para integrar esta población. Las ciudades de Turingia fueron ejemplo de ello.

A través de su consejo citadino -que deliberó sobre el tema en diversas sesiones- Weimar decidió integrar 1000 refugiados. Para tal, recibió los recursos del Estado Federal calculados precisamente para permitir que las ciudades cubrieran los gastos de vivienda, alimentación, documentación, transporte, formación lingüística y laboral, asistencia sanitaria, asesoría para el ingreso en el mercado laboral e integración escolar (de los menores) de este millar personas. El consejo citadino deliberó que se evitaría la formación de "guetos" migrantes: se optó por acondicionar residencias en diferentes espacios de la ciudad y contactar a vecinos que, voluntariamente, servirían de receptores y facilitadores de los procesos de integración de los nuevos vecinos. Así, Weimar desarrolló su propio modelo local de integración migratoria en el que absolutamente todos los recursos de bienestar social fueron entregados a los refugiados contando con recursos públicos del Estado alemán y de la Unión Europea.

\section{Hesse}

Nuestra segunda parada fue en el estado de Hesse (centro-oeste alemán), donde se localiza la ciudad de Frankfurt, considerada el corazón del capitalismo financiero de Europa (sede del Banco Central Europeo). Hesse es una región densamente industrializada que tuvo rol protagónico en la producción de armas militares en la Segunda Guerra Mundial. Por lo mismo, fue bombardeada incesantemente: sus principales ciudades perdieron la mayor parte de su patrimonio arquitectónico. La reconstrucción postguerra fue compleja: tanto por la falta de recursos materiales, como de mano de obra.

Para solucionar este último problema, los estados industriales pertenecientes a la República Federal de Alemania (la "Alemania Occidental"), como Hesse, crearon e implementaron políticas migratorias de corte utilitarista. Dichas políticas fueron aplicadas para reclutar población masculina económicamente activa a ser empleada en la reconstrucción del país y en la reactivación del cinturón industrial. La orientación "pragmática" de estas políticas suponía que el o la migrante solo sería aceptado si su presencia atendiera una necesidad (utilidad) económica específica (y debía dejar el territorio en el momento en que dejara de satisfacer esta utilidad). Este modelo se aplicó a través de los contratos de "trabajadores invitados", Guest-workers [Gastarbeiter, en alemán] (Schmidt, 1997), otorgados por el propio Estado. Estos establecían el deber del migrante de no emitir opiniones políticas y de devolverse a su país de origen una vez terminado el periodo 
contractual (López-Sala, 2005). A través de esta política, se reclutó una numerosa población turca que, a contracorriente de lo que esperaban los planificadores, terminó radicándose en el país a través de procesos de reunificación familiar (Velling, 1994).

En Hesse, nos dirigimos a la ciudad de Kassel (200.000 habitantes) que, durante toda la Guerra Fría, constituyó un territorio fronterizo: localizada en la frontera con la RDA. Kassel ha recibido migración turca desde la década de los $1960 \mathrm{~s}^{10}$; búlgara y somalí desde los 90 s y romaní desde los 2000 (Awojobi, 2016, p. 150). Esta población ha estado predominantemente asentada en el sector Nord-Holland de la ciudad, que devino un enclave migratorio. Desde 2015, también viven en Nord-Holland los refugiados sirios, africanos y migrantes del este europeo. Otro de los sectores de Kassel que se convirtió en enclave migrante turco desde los 60s, Brückenhof, es (desde 2016) también la principal área de arraigo de los refugiados afganos (Awojobi, 2016, p. 150).

Conversando sobre la crisis de refugiados con colegas investigadores de la Universidad de Kassel, supimos que entre 2015 y 2016 la ciudad hospedó en sus periferias a un gran campo de recepción de solicitantes de asilo y que la situación de la gente en estos campos fue también motivo de conmoción. Según la investigadora Sophia Pianwoski (Universidad de Kassel), tras la disolución del campo, la presencia de los nuevos refugiados ya no se sentía en las partes céntricas de la ciudad: su reasentamiento se dio predominantemente de forma segregada, en aquellos barrios periféricos que ya constituían "zonas migratorias" desde la reconstrucción alemana. La Dra. Angela Schrott (Universidad de Kassel) nos informó que la presencia de representantes de fuerzas políticas de extrema derecha en los escaños del poder legislativo federal (fenómeno que no se observaba desde la Segunda Guerra), contribuyó a legitimar la expresión pública de discursos de odio (racismo y antisemitismo). Las poblaciones migrantes y refugiadas han sido uno de los blancos de estos discursos políticos y se notaba, según ella, un creciente rechazo al uso de recursos públicos del Estado en la recepción de estas poblaciones en ciudades como Kassel.

Cruzando el centro de la ciudad, de camino al campus universitario, encontramos diversas calles en las que toda la vida comercial estaba dinamizada por los restaurantes, tiendas de ropa y de alimento regentados por migrantes turcos y chinos (además de otros países árabes y asiáticos) ¿Cómo se podría pensar la vida económica de la ciudad sin la contribución de esta población asentada allí desde hace décadas? Con todo, en las puertas de la segunda década del siglo XXI, el modelo de "integración" operante en las políticas migratorias de Kassel pareciera seguir actualizando la lógica utilitarista

${ }^{10}$ Actualmente, Hesse es el cuarto estado del país con más población turca. 
que marcó los programas de "guest workers" en el siglo pasado. Los útiles comercios migrantes ocupan el centro de la ciudad, pero las residencias de quienes los regentan se encuentran en periferia urbana. Los y las migrantes constituyen una población históricamente arraigada, pero parcialmente invisible. La política de arraigo de los nuevos refugiados reproduce esta máxima, empujando la nueva población a los márgenes de la ciudad.

\section{Renania del Norte-Westfalia}

Nuestra tercera parada fue en Renania del Norte-Westfalia (extremooccidente alemán). Allí, en los márgenes de los ríos Ruhr y Rin, estaban localizadas las más importantes minas de carbón europeas, subsidiarias de las revoluciones industriales y también de varios conflictos bélicos entre los siglos XIX y XX ${ }^{11}$. Casi todas las ciudades industriales del estado fueron fuertemente bombardeadas en la Segunda Guerra Mundial: aquí también, tanto la reconstrucción como la puesta en marcha de las industrias de carbón y acero utilizaron mano de obra migrante. Italianos, españoles y portugueses trabajaron extensamente en estos territorios. Pero los más numeroso fueron los turcos (bajo los contractos de "trabajadores invitados"). La presencia turca constituye, actualmente, una marca idiosincrásica de este estado que detiene la mayor concentración de migrantes de esta nacionalidad en Alemania (el 30\%).

Guiados por el Dr. Tobias Reu (Universidad de Bielefeld) y la investigadora Ping-Heng Chen (Universidad de Heidelberg), visitamos la ciudad de Duisburgo (500.000 habitantes), que fuera el principal enclave productor de acero y de la industria química alemana. Situada en la confluencia de los ríos Rin y Ruhr, Duisburgo detenta el mayor puerto fluvial de Europa. Pese a la reconversión, este sigue siendo uno de los espacios con mayor concentración industrial del continente. Los campos de refugiados que se multiplicaron en Alemania entre 2015 y 2016 no fueron tan numerosos en esta parte del país; pero la cuestión migrante no ha dejado de ser relevante aquí desde los años 60s.

En Duisburgo conocimos el modelo de gestión migratoria que más captó nuestra atención y al que decidimos registrar fotográficamente. En el distrito de Marxloh, encontramos un ejemplo contundente de un "enclave migrante": la concentración y el despliegue, en un espacio dado del entramado urbano, de una economía étnica que emplea trabajadores de esta misma minoría (Garcés, 2011) ${ }^{12}$ (imágenes 1, 2 y 3).

\footnotetext{
${ }^{11}$ Muchas de estas minas fueron cerradas y reconvertidas entre los siglos XX y XXI: contando con inversión estatal y de la Unión Europea. Actualmente, es posible visitar las fábricas cerradas, transformadas en parques y museos.

12 El concepto de economías de enclave étnico refiere a emprendimientos 1) desarrollados por migrantes; 2) con capital inicial o de giro migrante; 3) administrados, mantenidos y controlados por mano de obra migrante, y 4) destinados a un público consumidor migrante (Portes, Jenses, 1989).
} 


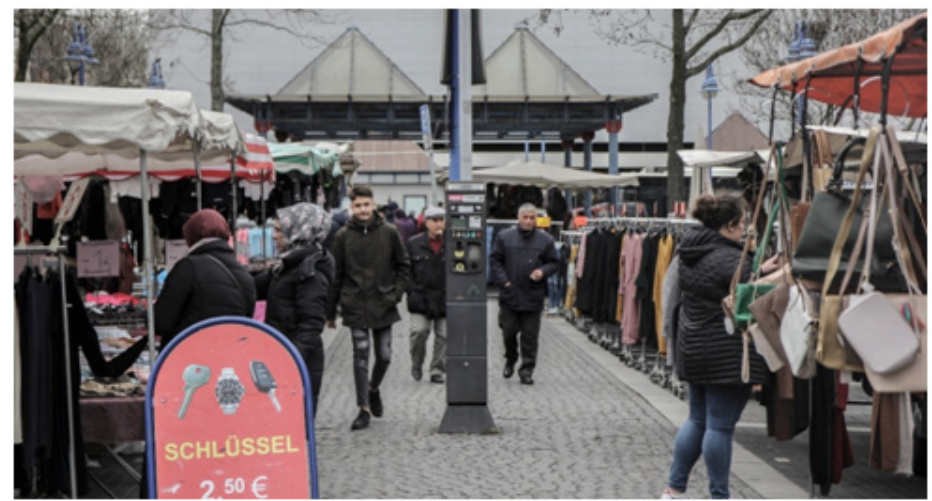

Imagen 1. Feria callejera en Marxloh (Duisburgo, Alemania).

Registro: Pablo Mardones (02/2019)

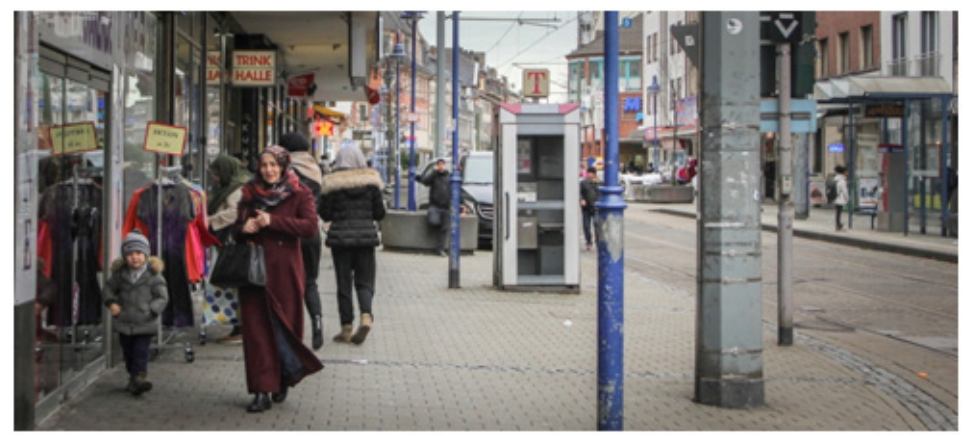

Imagen 2. Negocios de ropa usada en Weselwe Strasse, calle principal de Marxloh (Duisburgo, Alemania). Registro: Pablo Mardones (02/2019)

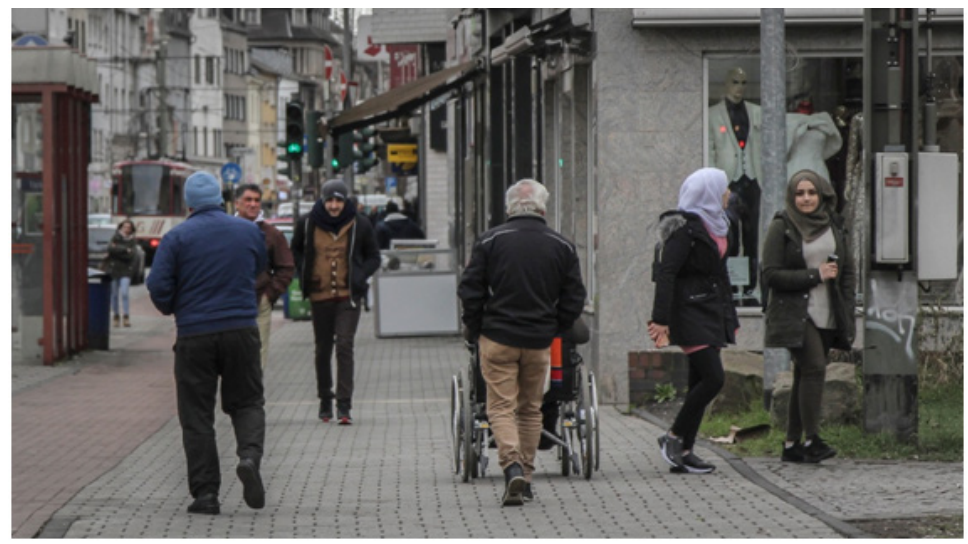

Imagen 3. Peatones en Weselwe Strasse, en Marxloh (Duisburgo, Alemania). Registro: Pablo Mardones (02/2019) 
Lo étnico del concepto suele hacer referencia a tres cosas que encontramos claramente ejemplificadas en Marxloh. En primero lugar, los migrantes "importan" desde los países de origen productos, prácticas y costumbres que serán vendidas como formas materializadoras de su "identidad" (imagen 4).

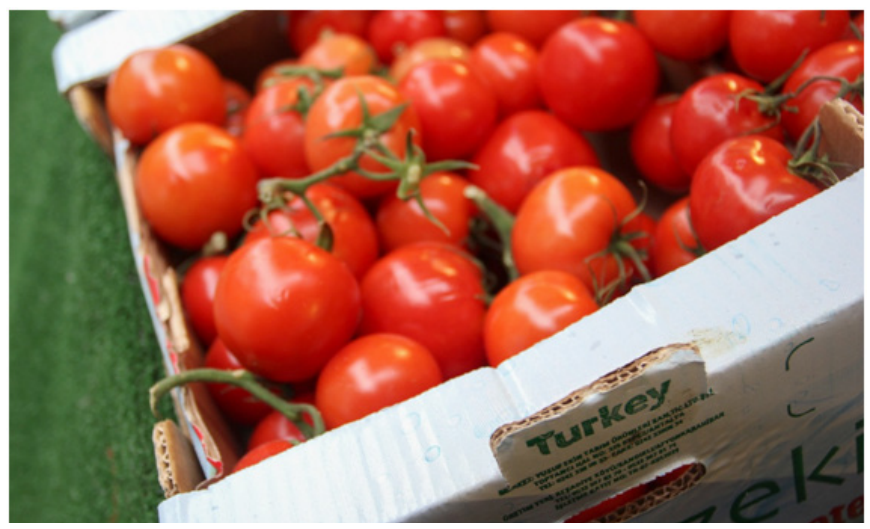

Imagen 4. Caja de tomates importados de Turquía, verdulería de Marxloh (Duisburgo, Alemania). Registro: Pablo Mardones (02/2019)

En segundo lugar, estos negocios dependen del recurso a cierto principio de autenticidad originaria de aquello que venden: el producto está validado no solamente como un valor de troca, sino, y fundamentalmente, como un valor de autenticidad (Light, 1972) (imágenes 5, 6 y 7).

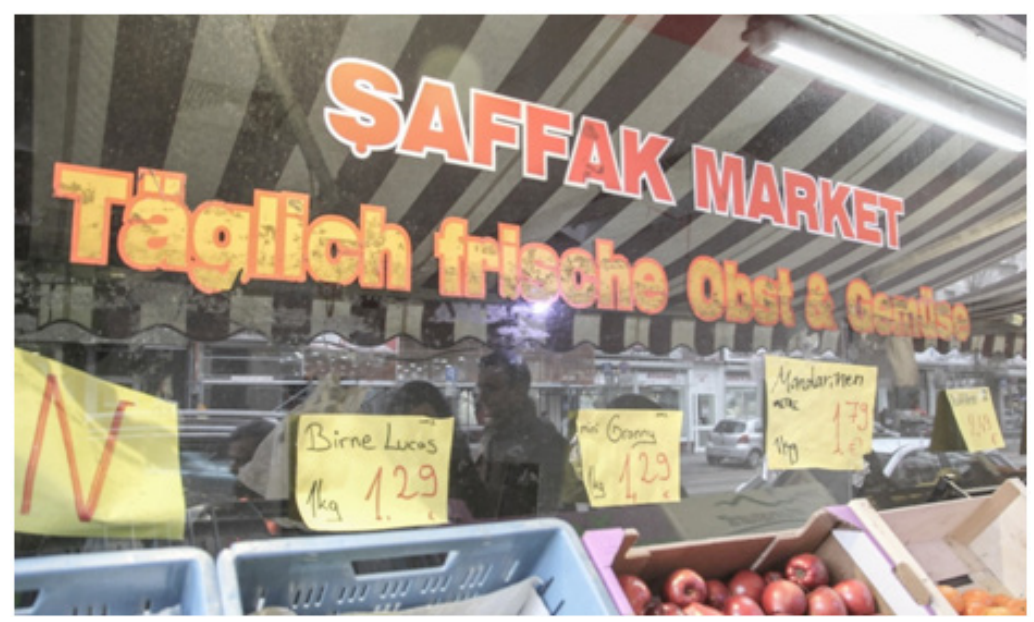

Imagen 5. Verdulería de nombre turco en Marxloh (Duisburgo, Alemania).

Registro: Pablo Mardones (02/2019) 


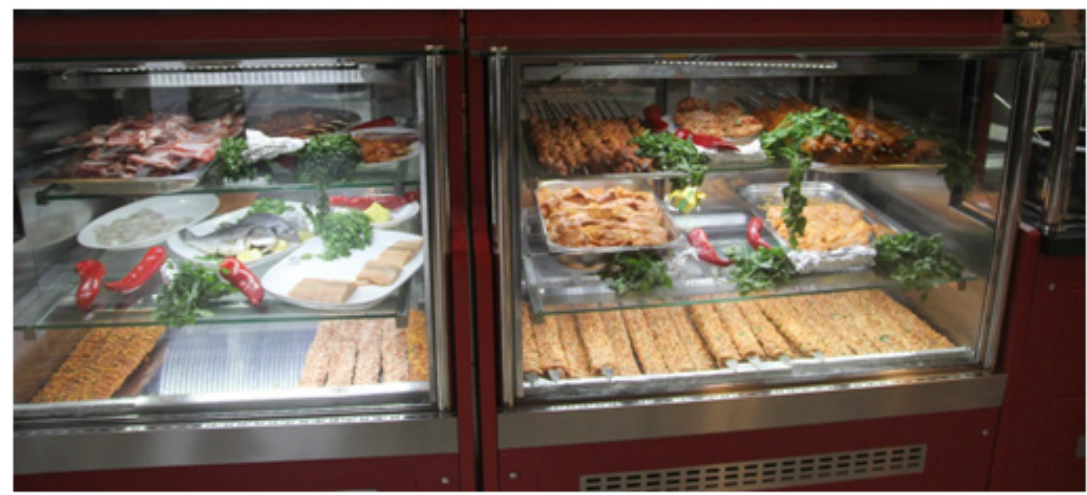

Imagen 6. Comidas típicas turcas en exposición, restaurant turco en Marxloh (Duisburgo, Alemania). Registro: Pablo Mardones (02/2019)

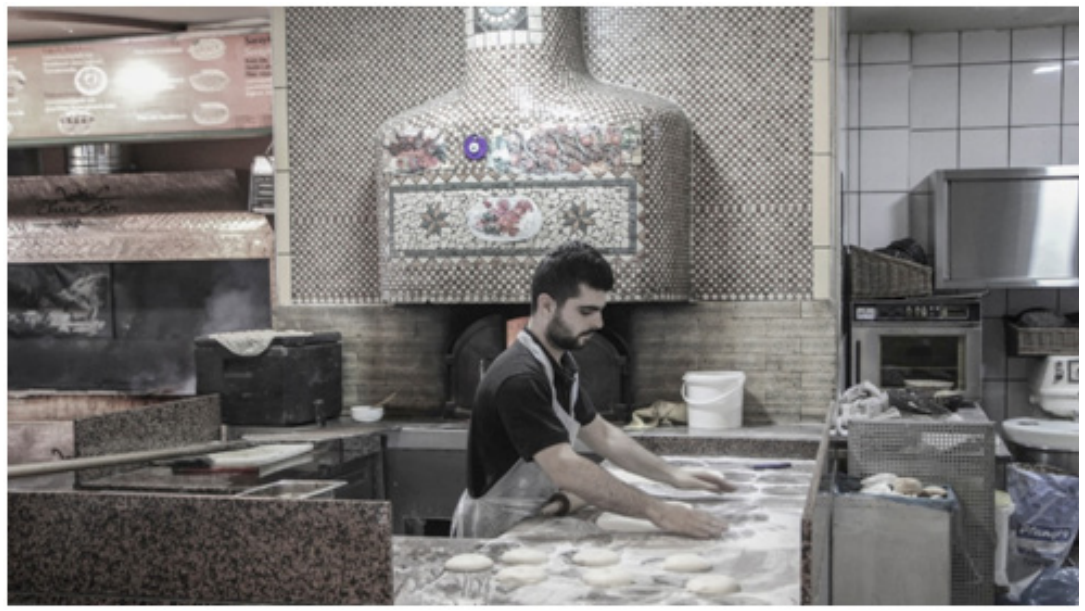

Imagen 7. Preparación de panes tradicionales turcos, restaurant de Marxloh (Duisburgo, Alemania). Registro: Pablo Mardones (02/2019)

En Marxloh -como también se observa en otros enclaves étnicos- el transnacionalismo comercial/identitario migrante constituye un punto de entrelazamiento entre diferentes esferas de la vida social. Entre ellas, la religiosa: el distrito alberga una de las más importantes organizaciones sociales de la migración turca en Alemania, articulada alrededor de las actividades de la mezquita Merkez ${ }^{13}$ (imagen 8). La mesquita fue construida por los migrantes con apoyo y auspicio del Estado alemán, de la Unión Europea y de la Unión

${ }^{13}$ La Mezquita Merkez fue inaugura en el segundo semestre de 2008 y es la más grande toda Alemania. 
Islámica Turca (DITIB), cuyas banderas flamean en la puerta principal del recinto religioso (imagen 9).

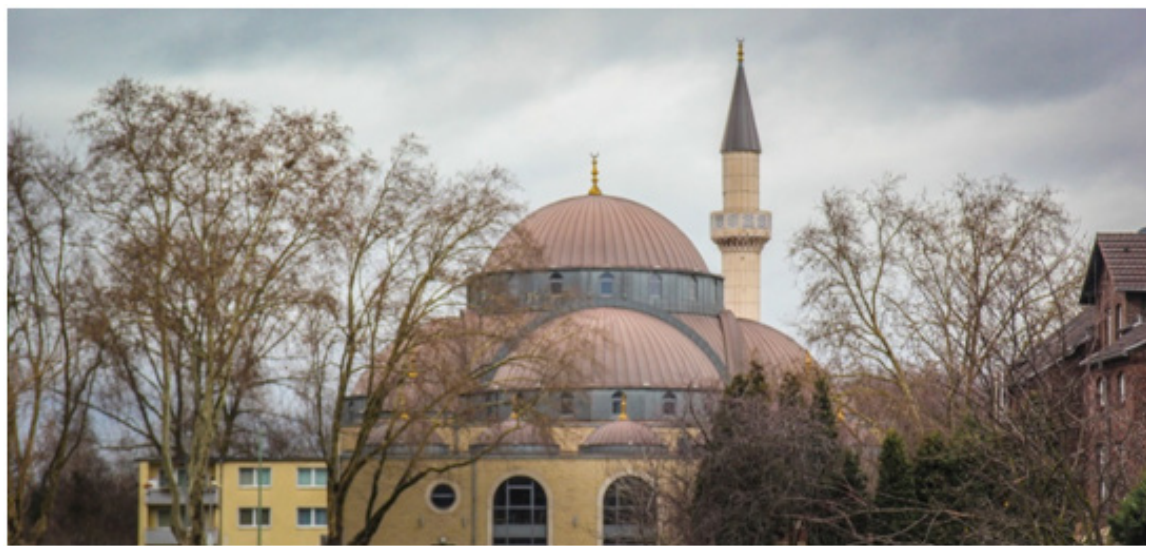

Imagen 8. Mezquita Merkez (Duisburgo, Alemania). Registro: Pablo Mardones (02/2019)

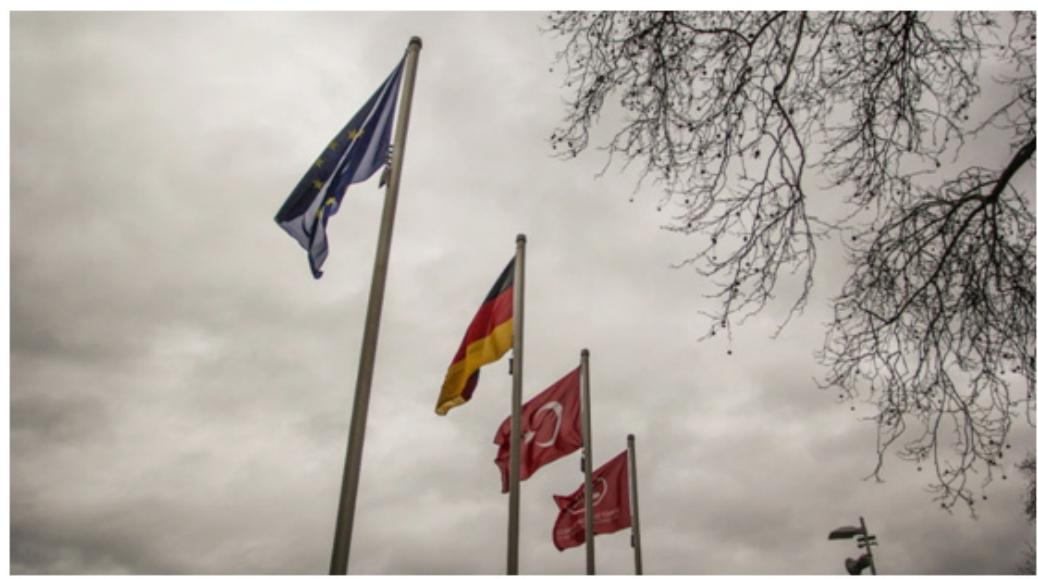

Imagen 9. Banderas de Alemania, Turquía, Unión Europea y de la Unión Islámica Turca (DITIB). Mezquita Mezkez en Marxloh (Duisburgo, Alemania).

Registro: Pablo Mardones (02/2019)

En tercer lugar, dichos negocios materializan una forma específica la alteridad social vivida por los y las migrantes como "otros", como diferenciados, de los autóctonos, lo que puede alimentar imaginarios de exclusión (Garcés, 2011). Este último aspecto es muy relevante en el caso de Marxloh: su estatus de "barrio de migrantes turco" le ha conferido fama en toda Alemania y también Europa. Políticos de la extrema derecha (y medios de comunicación alineados a sus ideas) desplegaron una campaña de desprestigio del distrito, 
asociándolo al crimen, suciedad urbana e inseguridad. Todo esto le rindió el título de "zona prohibida" [no-go zone] y la fama de ser el ejemplo de la condensación de "muchos de los problemas del país en lo que se refiere a la migración" (Schumacher, 2018).

Lejos de ser anodino, este discurso de odio mueve acciones de rechazo por parte de la población local en Marxloh, reencendiendo formas de nacionalismo que muchos daban por superadas en el país (imagen 10).

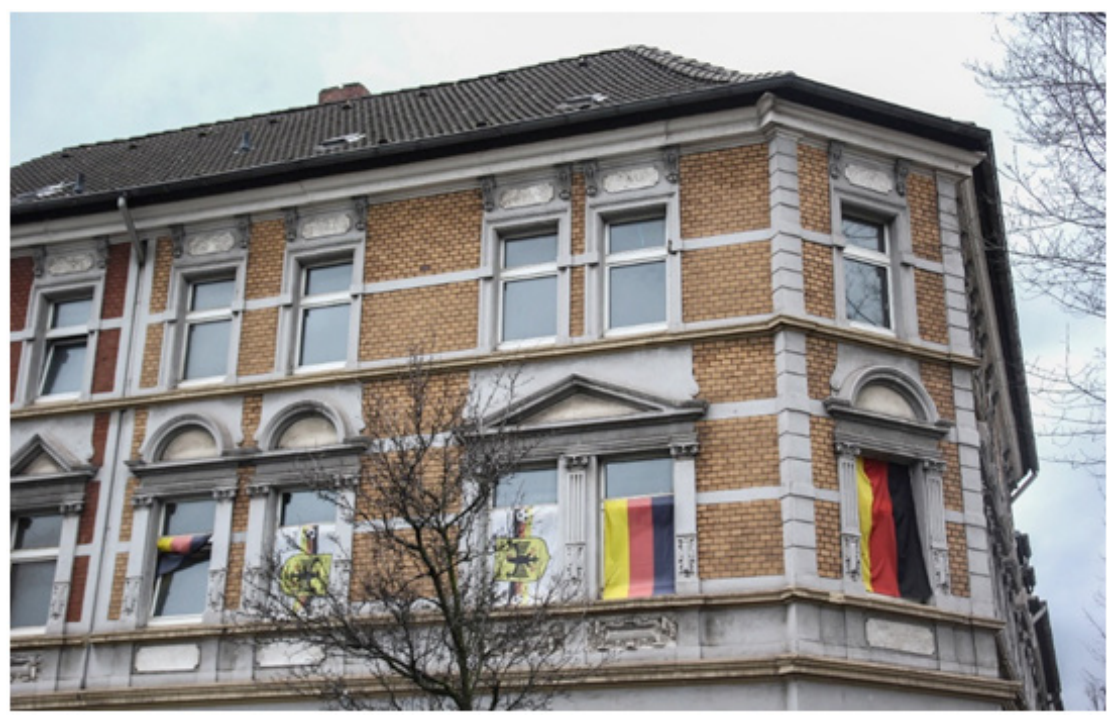

Imagen 10. Banderas alemanas en las ventanas residenciales de Marxloh (Duisburgo, Alemania). Registro: Pablo Mardones (02/2019)

\section{Cierre}

Nuestras observaciones dan cuenta de tres modelos diferenciados de configuración migrante en territorios alemanes. El modelo de Turingia refiere a un estado situado en la antigua Alemania Oriental, donde no se aplicaron las políticas utilitaristas de "trabajadores invitados" y que viene, desde los 1990s, Ilevando a cabo procesos de discusión y resignificación de la identidad local (en el marco de su integración a la economía capitalista). En ciudades de este estado como Weimar y Jena, observamos una disposición para pensar esta gestión de la crisis de refugiados (de 2015 y 2016) como parte de estos procesos de resignificación identitaria local. De ahí la propuesta de evitar modelos de segregación urbana que generen guetos migrantes.

El modelo de Hesse, y particularmente de Kassel, ciudad que constituía una frontera de la Alemania occidental con la oriental, nos habla de al 
menos cinco décadas de recepción de migrantes. Kassel recibió turcos para la reconstrucción postguerra desde los 50s, pero los segregó en la periferia (donde permanecen parcialmente invisibles para los habitantes de las zonas céntricas). Con todo, permitió la proliferación de los comercios migrantes en el centro, lo que remite a la noción utilitarista que vertebró la política alemana de trabajadores invitados. Kassel recibió muchos refugiados en la crisis de entre 2015 y 2016, pero optó por seguir este mismo modelo de marginación, segregando los nuevos habitantes en los asentamientos periféricos de trabajadores extranjeros.

El modelo de Renania del Norte-Westfalia, en extremo occidente de Alemania, nos muestra la configuración de las políticas migratorias en las zonas pujantemente industriales, que requirieron de muchísimos trabajadores migrantes en la reconstrucción postguerra y también para el desarrollo económico industrial posterior. Es la región con más población turca en Alemania, pero no recibió refugiados en 2015. Segregó históricamente a sus migrantes en enclaves étnicos y, ahora, estas localidades son nacionalmente tratadas por sectores nacionalistas como "indeseables" y como "un problema". Este tercero ejemplo nos entrega la imagen de la conversión de un barrio migrante en un elemento de rechazo simbólico a escalas nacionales: un proceso de materialización de los discursos del odio que deniegan el derecho de pertenencia y arraigo a poblaciones en cuyos brazos descansaron la reconstrucción de Alemania en las últimas décadas.

Así, pareciera haber mejores disposiciones para una integración consensuada de la nueva población refugiada en Alemania en aquellos espacios donde los migrantes no han sido históricamente reconocidos solamente desde una perspectiva utilitarista. Los ejemplos permiten comprender el impacto de larga duración de políticas migratorias con esta orientación segregacionista y permiten deconstruir el discurso de liderazgos políticos sudamericanos, como el del actual presidente de Chile, Sebastián Piñera, quien defiende el modelo utilitarista alemán como ejemplo a ser aplicado en el Cono Sur.

La gestión de la crisis de los refugiados en Alemania entre 2015 y 2016 contó con sendas inversiones públicas tanto del Estado Federal, como de la Unión Europea. El programa desarrollado en Weimar (Turingia) es el ejemplo más claro. Pero también en Kassel fueron fondos públicos que articularon redes de seguridad social, empleo y arraigo migrante. Así, una de las únicas regularidades en estos tres casos (muy heterogéneos en sus aspectos compositivos) es, precisamente, el hecho de que se destinan recursos públicos activamente para la composición y aplicación de los modelos de gestión de la cuestión migratoria. Incluso en Marxloh (Duisburgo, el modelo menos integrativo de los tres), fue el Gobierno alemán el que financió la construcción de la Mezquita. Se observa que esta regularidad tiene un carácter histórico. 
Desde la reconstrucción post Segunda Guerra Mundial, la gestión migratoria es un asunto estatal para el cual se destinan importantes recursos anualmente.

Estas constataciones nos permiten cuestionar el discurso hegemónico en los países del Cono Sur Americano donde el giro a la derecha se acompaña no solamente de una lógica de demonización del Estado (alimentándose la creencia en su incapacidad como gestor de realidades y recursos sociales), sino también de la aseveración de la idea de que, en lo concierne a la cuestión migrante, la inversión pública debe reducirse a la compra y aplicación de armas de control fronterizo y herramientas de vigilancia de las movilidades humanas.

Es del todo probable que estas gestiones migratorias con fondos estatales que observamos en Alemania -considerada por muchos una de las principales democracias capitalistas del mundo- fuesen tachadas de "ideas comunistas" si fueran propuestas actualmente en países como Argentina, Brasil y Chile.

\section{Referencias}

AWOJOBI, Oladayo Nathaniel. The Economic Impact of Inmigration on Kassel, Germany: an Observation. International Journal of Economics, Commerce and Management, v. 4, n. 11, p. 142-157, 2016.

ANDERSON, Benedict. Comunidades imaginadas. Reflexiones sobre el origen y la difusión del nacionalismo. México DF: FCE, 1993.

BRUBAKER, Roger. Citizenship and Nationhood in France and Germany. Cambridge: Harvard University Press, 1992.

BURAWOY, Michael. The extended case method. Sociological theory, v. 16, n. 1, p. 4-33, 1998.

DESTATIS [Statistisches Bundensamt]. Persons seeking for protection, by protection status (2007-2017). 2019a. Disponible en: <https://www.destatis. de/EN/FactsFigures/SocietyState/Population/MigrationIntegration/Tables ProtectionSeekers/TimeSeriesProtectionsStatus.html >. Acceso en: 14.02.2019.

DESTATIS [Statistisches Bundensamt]. Migration in 2017: immigration to Germany exceeding emigration by 416,000. 2019b. Disponible en: <https://www. destatis.de/EN/FactsFigures/SocietyState/Population/Migration/Migration.html>. Acceso en: 14.02.2019.

DESTATIS [Statistisches Bundensamt]. Migration \& Integration. 2019c. Disponible en: $\quad<$ https://www.destatis.de/EN/FactsFigures/SocietyState/Population/ MigrationIntegration/MigrationIntegration.html >. Acceso en: 14.02.2019.

EVENS, Theodore; HANDELMAN, Don. The Ethnographic Praxis of the Theory of Practice. In: EVENS, Theodore; HANDELMAN, Don (eds.). The Manchester School. Practice and Ethnographic Praxis in Anthropology. New York: Berghahn Books, 2006, p. 1-12. 
FRANKENBERG, Ronald. A Bridge over Troubled Waters, or What a Difference a day Makes. In: EVENS, Theodore; HANDELMAN, Don (eds.). The Manchester School. Practice and Ethnographic Praxis in Anthropology. New York: Berghahn Books, 2006, p. 202-222.

GANG, Ira; STUART, Robert. Mobility where mobility is illegal: Internal migration and city growth in the Soviet Union. Journal of Population Economics, v. 12, n. 1, p. 117-134, 1999.

GARCÉS, Alejandro. De enclave a centralidad. Espacio urbano, comercio y migración peruana en Santiago de Chile. Gazeta de Antropología, v. 2, n. 2, s/p, 2011.

GLAESER, Andreas. An Ontology for the Etnographic Analysis of Social Processes. Extending the Extended-Case Method. In: EVENS, Theodore; HANDELMAN, Don (eds.). The Manchester School. Practice and Ethnographic Praxis in Anthropology. New York: Berghahn Books, 2006, p. 64-93.

GLUCKMAN, Max. Ethonographic Data in British Social Anthropology. In: EVENS, Theodore; HANDELMAN, Don (eds.). The Manchester School. Practice and Ethnographic Praxis in Anthropology. New York: Berghahn Books, 2006, p. 13-22.

GUBER, Rosana. La etnografía: método, campo y reflexividad. Buenos Aires: Editorial Norma, 2001.

HOBSBAWN, Eric. Naciones y Nacionalismos desde 1780. Barcelona: Crítica, 1998.

INTERNATIONAL ORGANIZATION FOR MIGRATION [IOM]. World Migration Report. Ginebra: IOM, 2018.

KEMPNY, Marian. History of Manchester "School" and the Extended Case Method. In: EVENS, Theodore; HANDELMAN, Don (eds.). The Manchester School. Practice and Ethnographic Praxis in Anthropology. New York: Berghahn Books, 2006, p. 180-201.

KRETSEDEMAS, Philip; BROTHERTON, David. Immigration Policy in the Age of Punishment: Detention, Deportation, and Border Control. Columbia: Columbia University Press, 2018.

LIGHT, Ivan. Ethnic enterprise in America: business and welfare among Chinese, Japanese, and Blacks. Berkeley: University of California Press, 1972.

LÓPEZ-SALA, Ana María. Inmigrantes y Estados: la respuesta política ante la cuestión migratoria. Barcelona: Anthropos, 2005.

MITCHELL, Clyde. Case and Situation Analysis. In: EVENS, Theodore; HANDELMAN, Don (eds.). The Manchester School. Practice and Ethnographic Praxis in Anthropology. New York: Berghahn Books, 2006, p. 23-44.

PORTES, Alejandro; JENSEN, Leif. The enclave and the entrants: patterns of ethnic enterprise in Miami before and after Mariel. American Sociological Review, v. 54, n. 6, p. 929-949, 1989.

SCHMIDT, Christoph. Immigrant performance in Germany: Labor earnings of ethnic German migrants and foreign guest-workers. The Quarterly Review of Economics and Finance, v. 37, p. 379-397, 1997. 
SCHUMACHER, Elizabeth. German presidentvisits "no-go" Duisburgneighborhood. Deutsche Welle. 18.03.2018. Disponible en: <https:/www.dw.com/en/ german-president-visits-no-go-duisburg-neighborhood/a-42960955>. Acceso en: 15.02.2019.

VELLING, Johannes. The determinants of family reunification among German guest-workers. Vierteljahrshefte zur Wirtschaftsforschung, v. 63, n. 1/2, p. 126132, 1994.

ZAPATA-BARRERO, Ricard. Ciudadanía, democracia y pluralismo cultural: hacia un nuevo contrato social. Barcelona: Anthropo, 2001. 